\title{
Priority effects are affected by precipitation variability and are stronger in exotic than native grassland species
}

\author{
Kaitlin M. Goodale $\mathbb{D} \cdot$ Brian J. Wilsey
}

Received: 13 April 2017 / Accepted: 1 February 2018/Published online: 19 February 2018

(C) The Author(s) 2018. This article is an open access publication

\begin{abstract}
Exotic perennial grassland species often green up earlier than their native counterparts, allowing them to gain an advantage by dominating resources early (priority effects). Precipitation variability is expected to increase with climate change, and may alter the strength of priority effects. We hypothesized that exotics will have stronger priority effects than natives, precipitation variability will impact the strength of priority effects, and precipitation variability will impact the priority effects of native species more than those of exotics. We seeded one of five native or five exotic grassland species from the Central U.S. spanning multiple functional groups 28 days prior to a native seed mix. Priority effect strength was determined by how much establishment and diversity was reduced in the mix compared to controls (no species seeded before mix). We crossed these priority effect treatments with three water variability treatments, one low variability, and two
\end{abstract}

Communicated by Jesse Kalwij.

Electronic supplementary material The online version of this article (https://doi.org/10.1007/s11258-018-0806-6) contains supplementary material, which is available to authorized users.

K. M. Goodale $(\bowtie) \cdot$ B. J. Wilsey

Department of Ecology, Evolution, and Organismal

Biology, Iowa State University, 251 Bessey Hall, Ames,

IA 50011, USA

e-mail: kmbarber@iastate.edu high variability with alternate timing. Exotic species had stronger priority effects than natives, and decreased diversity and establishment from the seed mix. High variability precipitation when the growing season began dry significantly increased priority effects compared to low variability and high variability beginning wet. We found no significant evidence for a more pronounced impact of precipitation on native species, but trends suggest future studies may reveal significant interactions. Although future research in the field over multiple growing seasons is needed, our results suggest priority effects of exotics in Central U.S. grasslands are independent of precipitation timing and therefore likely to persist under changing climates.

Keywords Invasive species - Community assembly · Precipitation · Climate variability · Priority effect

\section{Introduction}

The order that species arrive during community assembly can affect the resulting community structure, leading to priority effects. Priority effects occur when the effect of an early arriving species on later colonists is stronger than when they all arrive at the same time (Fukami 2015), or when 'species that are present at 
some early phase of community development influence other species abundances that arrive at some later time' (Morin 1999), resulting in a change in the community composition (Polley et al. 2006). These effects can be inhibitory or facilitative, as early arriving species can have a negative or positive effect on the species that arrive later (Fukami 2015). In inhibitory priority effects, early arriving species have a competitive advantage over later arriving species if they take up resources and attain a larger size prior to later species (Harper 1961).

In grassland systems, exotic species dominance and invasion success can in part be attributed to inhibitory priority effects where exotics show large priority effects over establishing native grassland species, reducing native plant growth and diversity (Grman and Suding 2010; Martin and Wilsey 2012; Dickson et al. 2012; Ulrich and Perkins 2014; Wilsey et al. 2015; Stuble and Souza 2016). When native grassland species arrive first they can exclude exotic invaders (Abraham et. al. 2009; Vaughn and Young 2015), but this is not often the case in many perennial grassland systems when exotic species demonstrate earlier phenology than natives (Wilsey et al. 2011; Wolkovich and Cleland 2011). Exotic grassland species have higher seedling growth rates, earlier emergence dates and higher germination rates than native counterparts (Wainwright and Cleland 2013; Wilsey et al. 2015). When exotic perennial grassland species arrive before natives during assembly it can lead to lower species diversity and near monocultures (Dickson et al 2012; Wilsey et al. 2015). Exotic species can significantly alter later community composition, so knowing when priority effects are the strongest can help us pinpoint the conditions when exotic species pose the largest threats.

Priority effects can vary in strength not just in response to phenological traits, but also to abiotic conditions (Jarchow and Liebman 2012; Kardol et al 2013; Tucker and Fukami 2014). Inhibitory priority effects might weaken under stressful conditions (Chase 2003; Tucker and Fukami 2014). Support for this has been found in a variety of systems including the vernal pools of California where priority effects were found to be strongest under optimal conditions (Collinge and Ray 2009). Recent work from Brandt et al. (2016) suggests that priority effects can impact macro-evolutionary history, increasing the abundance and richness in clades that arrived earliest to New
Zealand alpine forests. This priority effect was stronger in high than low resource environments. Similarly, nutrient additions can increase the strength of priority effects, allowing early arriving species to gain higher levels of resources compared to a less enriched environment (Jarchow and Liebman 2012; Kardol et al 2013). When nutrients are abundant, even slight differences between early community compositions can lead to distinct community formations (Houseman et al. 2008). Martin and Wilsey (2012) showed that priority effects were important in both a high productivity and low productivity grassland site, suggesting that in some scenarios the strength of the priority effect can override abiotic differences, making assembly history more important to resulting community structure.

Climate change is predicted to increase the variability of rainfall and extreme weather events (Kharin et al. 2007; Allan and Soden 2008; Berg et al. 2013) and not just the overall availability of water. Priority effects for native grasses against invaders have been found to weaken when rainfall was increased (Young et al. 2015). Schantz et al. (2015) found priority effects of perennial grass species over annuals diminished when water was added as annuals were able to better utilize the increased resource, nullifying the priority effect. However, there has been little work on the impact of water variability on priority effects. Increased variability in rainfall can have large impacts on community composition and species diversity independent of rainfall amount (Knapp et al. 2002). Jones et al. (2016) conducted a 15-year precipitation variability grassland experiment and found that increased rainfall variability led to an increase in forb abundance and richness while dominant grasses remained relatively stable. Over time, rainfall variability led to the development of distinct communities as forb diversity increased, suggesting that rainfall variability plays a role in community assembly. Successful exotics, however, commonly have a wide niche breadth, either due to higher plasticity or generalist life history traits, meaning that increasing environmental variability may have little effect on exotic dominance (van Kleunen et al. 2015). This larger niche width may make the strength of priority effects from exotics more resistant to changes in extreme rainfall events.

We compared the strength of priority effects between native and exotic grassland plant species 
under varying water variability treatments in a greenhouse experiment. Past research found that exotic perennial grassland species exhibit larger effects on later establishing communities when they are seeded early compared to when all species are seeded simultaneously, and that these priority effects are much stronger for exotics than for native counterparts (Dickson et at. 2012; Martin and Wilsey 2012). Here, we extend this work by testing how these effects of early emerging species on community establishment are impacted by climate variability (i.e., increased rainfall variability). To create priority effects, we seeded one of five native or five exotic perennial grassland species from the Central U.S. 28 days before adding a 39 native-species seed mix. Priority effect strength was measured as the impact of these early species on the establishment of a later arriving native seed mix compared to a control (no early arriving species present). This treatment was crossed with a water variability treatment with three levels: a low variability treatment, and two high variability treatments that varied the timing of dry periods. All water variability treatments had equal average frequency of watering during the growing season, and only variability changed. We hypothesized that (a) exotics will consistently have larger priority effects than natives, (b) higher variability in soil moisture will reduce priority effects and increase diversity, and (c) that water variability treatments will have a larger impact on native species than exotics.

\section{Methods}

We tested our hypotheses in a greenhouse experiment in the Bessey greenhouse at Iowa State University, Iowa, USA. The experimental two-way factorial design consisted of a priority species treatment (one of five native or five exotic species or nothing as a control, Table 1) crossed with a water variability treatment. Water variability treatments were high variability starting with a wet period, high variability starting with a dry period, and low variability with a consistent watering frequency. Each priority species treatment had two replicates with seven replicate controls per water treatment, for a total of 81 experimental pots $(10$ species $\times 2$ replicates +7 controls $=27$ priority species treatments, 27 priority species treatments $\times 3$ water treatments $=81$ pots).
We used large pots $(27.5 \mathrm{~cm}$ diameter, $30 \mathrm{~cm}$ deep) filled with field soil for the experiment. The soil was not fertilized during or prior to the experiment. Top soil was taken from a local Iowa farmland typical of soil in the area and homogenized. Preliminary analysis showed the soil had a $\mathrm{pH}$ of $7.72,1.36 \%$ total carbon, and $0.08 \%$ total nitrogen. Soil was potted in April 2015 , and weeds were hand removed before the start of the experiment. A few additional weeds were removed during the experiment as needed.

Native priority species used are all native to North America and occur in Central U.S. prairies, while exotic priority species are not native to North America and are on national invasive species lists (Swearingen 2008). Exotic priority species were paired to a native priority species from the same tribe if possible, and always to the same family and ecological functional group (Table 1) to compare native and exotic species with minimal confounding variables present. These species pairs were from a longer species list used in Wilsey et al. (2015). We chose a species pair from each of the main functional groups $\left(\mathrm{C}_{3}\right.$ grasses, $\mathrm{C}_{4}$ grasses, legumes, and forbs) with two pairs for $\mathrm{C}_{3}$ grasses. All the species used were perennial. Priority species treatments were established by adding 100 seeds of one of each priority species to the bare soil in each pot on May 18, 2015. During the first 4 weeks, priority species were allowed to establish and were watered daily until seedlings emerged. The native seed mix consisted of 39 native perennial prairie species, and was added 28 days later on June 15, 2015 (Online Resource 1), with 10 seeds per species. The 21 control pots received the native seed mix alone on the same date.

Water variability treatments were started on June 15,2015 , at the time of the seed mix addition. The three water variability treatments consisted of a low variability and two high variability treatments. The low variability treatment (hereafter referred to as $\mathrm{A}_{\text {low }}$ ) was watered every 3 or 4 days ( 3 times over the course of 10 days). The two high variability treatments varied in timing, with high variability starting with high frequency or wet conditions (hereafter referred to as $\left.\mathrm{B}_{\text {High-wet }}\right)$ and high variability starting with low frequency or dry conditions (hereafter referred to as $\mathrm{C}_{\text {High-dry }}$ ). We included two variations of high variability to determine if increased variability, regardless of timing, would impact priority effects consistently. During high frequency or wet conditions, pots were 
Table 1 Paired native and exotic priority species representing the four main functional groups $\left(\mathrm{C}_{4}\right.$ designates $\mathrm{C}_{4}$ grasses, $\mathrm{C}_{3}$ designates $\mathrm{C}_{3}$ grasses, $\mathrm{F}$ designates forbs, and $\mathrm{LF}$ designates leguminous forbs). All species are perennial

\begin{tabular}{lll}
\hline Exotic priority species & Native priority species & Functional group \\
\hline Eragrostis curvula & Sporobolus cryptandrus & $\mathrm{C}_{4}$ \\
Festuca arundinacea & Elymus trachycaulus & $\mathrm{C}_{3}$ \\
Bromus inermis & Elymus canadensis & $\mathrm{C}_{3}$ \\
Cichorium intybus & Ratibida columnifera & $\mathrm{F}$ \\
Lotus corniculatus & Astragalus racemosus & $\mathrm{LF}$ \\
\hline
\end{tabular}

watered every 2 days (5 times over the course of 10 days). During low frequency or dry conditions, pots were watered every 10 days (1 time over the course of 10 days). High and low frequencies were switched every 30 days over the course of 120 days of the growing season. Therefore, the $\mathrm{B}_{\text {High-wet }}$ treatment spent the first 30 days under high frequency watering, the second 30 days under low frequency, the third 30 days under high frequency and the final 30 days under low frequency, while the $\mathrm{C}_{\text {High-dry }}$ underwent the reverse.

Our treatments changed the variability in watering but not the mean. All pots had the same total water amount, and were watered 36 total times to field capacity over the course of the experiment. Watering frequency (calculated as the days between watering) had a standard deviation of 0.478 and a coefficient of variation of 14.3 for the $A_{\text {low }}$ treatment, and a standard deviation of 3.024 and a coefficient of variation of 90.7 for $\mathrm{B}_{\text {High-wet }}$ and $\mathrm{C}_{\text {High-dry }}$.

\section{Sampling design}

Sampling of soil moisture and biomass by species was done at the end of the last watering interval to reduce disturbance. Over the last 10 days of watering treatments, we took a 4-cm-deep core from each pot every other day that was weighed wet, then dried for 3 days at $60{ }^{\circ} \mathrm{C}$, and weighed again to get a measure of gravimetric soil moisture for each watering frequency (Topp 1993). Aboveground biomass of all species in each pot was harvested at the end of the growing season over the 14th, 15th, and 16th of October 2015. Each pot was harvested by species and clipped at the soil surface, and then dried for 3 days at $60{ }^{\circ} \mathrm{C}$ and weighed. We measured priority effects as the impact of the priority species on biomass of the seed mix. We used diversity measures of species richness and Simpson's diversity $\left(1 / \sum p_{i}^{2}\right.$ where $p_{\mathrm{i}}$ is relative abundance) to estimate differences in final diversity across treatments. Simpson's diversity takes relative abundance into account, while species richness gives more weight to rare species. We additionally measured biomass of the priority species to compare mechanisms behind priority effects.

\section{Statistical analysis}

Gravimetric soil moisture was compared across water variability treatments at the end of a 10-day cycle of drying using an analysis of variance across water variability treatments. We used a two-way mixed model ANOVA using PROC MIXED in SAS (version 9.4) on our response variables: seed mix biomass, priority species biomass, total biomass, Simpson's diversity, and species richness. Priority species (native, exotic, or control) and water variability $\left(\mathrm{A}_{\mathrm{Low}}\right.$, $\mathrm{B}_{\text {High-wet }}$, or $\left.\mathrm{C}_{\text {High-dry }}\right)$ were our fixed effects and priority species identity was a random effect to account for variation at the species level. Seed mix biomass, total biomass, and species richness were $\ln$ transformed to improve normality. Priority species and water variability treatment levels were compared with Tukey's tests when effects were significant. Priority species biomass was $\ln$ transformed to improve normality, and we removed control treatments as they had no priority species added (total pots $=60$ ). To determine if species composition differed across priority species and water variability treatments, we used NMDS ordination and a multiresponse permutation procedure (MRPP) using PCORD, using the Bray-Curtis dissimilarity index 
(McCune and Grace 2002) on biomass from the seed mix at the species level. We included only species that established from the added mix (i.e., excluding priority effect species). We omitted pots that were monocultures (only species was the priority effect species), decreasing the native priority species pot number to 28 out of 30 and the exotic priority species pot number to 12 out of 30 . These omissions were relatively equal across watering treatments. A scree plot indicated a 3-dimensional solution.

\section{Results}

Seed mix biomass

Biomass from the seed mix was significantly different across priority species treatments and water variability treatments (Table 2). Seed mix biomass was highest in control pots with no priority effect species (Tukey's tests, $p$ values $<0.001$ ), and was greatly reduced in pots treated with exotic priority species (Fig. 1a). In 18 out of 30 pots, exotic priority species formed monocultures, completely preventing native seed mix emergence. The native priority species treatment showed intermediate seed mix biomass levels (Fig. 1a). Biomass from the seed mix was also affected by water variability treatments (Fig. 2a). The $\mathrm{C}_{\text {High-dry }}$ treatment had lower seed mix biomass than $\mathrm{B}_{\text {High-wet }}$ and $\mathrm{A}_{\text {low }}$ water variability treatments (Tukey's tests, $p=0.002$ and $p=0.006$, respectively). The interaction between water variability and priority species treatments was not significant $\left(F_{4,42}=2.33\right.$, $p=0.071)$ (Table 3).

Water variability treatments significantly affected gravimetric soil moisture. Moisture was significantly different across water frequency treatments $\left(F_{2,78}=\right.$ 4.23, $p=0.018$ ) where pots receiving water every other day were significantly wetter than those receiving water once every 10 days (Fig. 3). There was a drop in soil moisture for all water variability treatments between days four and six due to high temperatures. All pots experienced this variation in stress due to day-to-day temperature variability, and suffered no visible biomass loss or species loss due to this event alone.
Table 2 ANOVA Table and contrasts across priority species treatments (native, exotic and control) and the water variability treatments $\left(\mathrm{A}_{\text {low }}, \mathrm{B}_{\text {High-wet }}\right.$, and $\left.\mathrm{C}_{\text {High-dry }}\right)$ for $\ln$ transformed seed mix biomass (g), log transformed species richness, Simpson's diversity, log transformed total biomass (priority species biomass + seed mix biomass), and log transformed priority species biomass $(\mathrm{g})$. Seed mix biomass is the total biomass from the seed mix seeded 28 days following the priority species. Tukey's tests compared priority species and water variability treatments when main effects were significant. Priority species biomass is the biomass of the single species planted first (native or exotic)

\begin{tabular}{|c|c|c|c|c|c|c|c|c|c|c|c|c|}
\hline \multirow[t]{2}{*}{ Source } & \multirow[t]{2}{*}{ DF } & \multicolumn{2}{|c|}{$\begin{array}{l}\text { Seed mix } \\
\text { biomass }\end{array}$} & \multicolumn{2}{|c|}{ Species richness } & \multicolumn{2}{|c|}{$\begin{array}{l}\text { Simpson's } \\
\text { diversity }\end{array}$} & \multicolumn{2}{|c|}{ Total biomass } & \multirow[t]{2}{*}{ DF } & \multicolumn{2}{|c|}{$\begin{array}{l}\text { Priority } \\
\text { species } \\
\text { biomass }\end{array}$} \\
\hline & & $F$ & $P$ & $F$ & $P$ & $F$ & $P$ & $F$ & $P$ & & $F$ & $P$ \\
\hline Priority species & 2,42 & 94.43 & $<0.001$ & 50.01 & $<0.001$ & 25.68 & $<0.001$ & 27.33 & $<0.001$ & 1,24 & 10.96 & 0.003 \\
\hline Water variability & 2,42 & 7.92 & 0.001 & 10.25 & $<0.001$ & 2.66 & 0.082 & 0.48 & 0.621 & 1,24 & 1.92 & 0.169 \\
\hline $\begin{array}{l}\text { Priority species } \times \\
\text { Water variability }\end{array}$ & 4,42 & 2.33 & 0.071 & 0.95 & 0.446 & 1.24 & 0.310 & 2.06 & 0.104 & 1,24 & 3.28 & 0.055 \\
\hline \multicolumn{13}{|c|}{ Priority effect treatment Tukey's test } \\
\hline Exotic versus native & 42 & 7.96 & $<0.001$ & 8.21 & $<0.001$ & 2.9 & 0.016 & 2.45 & 0.048 & & & \\
\hline Exotic versus control & 42 & 13.66 & $<0.001$ & 8.9 & $<0.001$ & 7.12 & $<0.001$ & 7.25 & $<0.001$ & & & \\
\hline Native versus control & 42 & 5.94 & $<0.001$ & 1.16 & 0.486 & 4.22 & $<0.001$ & 4.73 & $<0.001$ & & & \\
\hline \multicolumn{13}{|c|}{ Water treatment Tukey's Test } \\
\hline$A_{\text {Low }}$ versus $B_{\text {High-wet }}$ & 42 & -0.38 & 0.925 & -1.31 & 0.399 & & & & & & & \\
\hline$A_{\text {Low }}$ versus $C_{\text {High-dry }}$ & 42 & -3.24 & 0.006 & -3.1 & 0.01 & & & & & & & \\
\hline$B_{\text {High-wet }}$ versus $C_{\text {High-dry }}$ & 42 & -3.62 & 0.002 & -4.41 & $<0.001$ & & & & & & & \\
\hline
\end{tabular}

Bold values indicate $p$ values $<0.05$ 

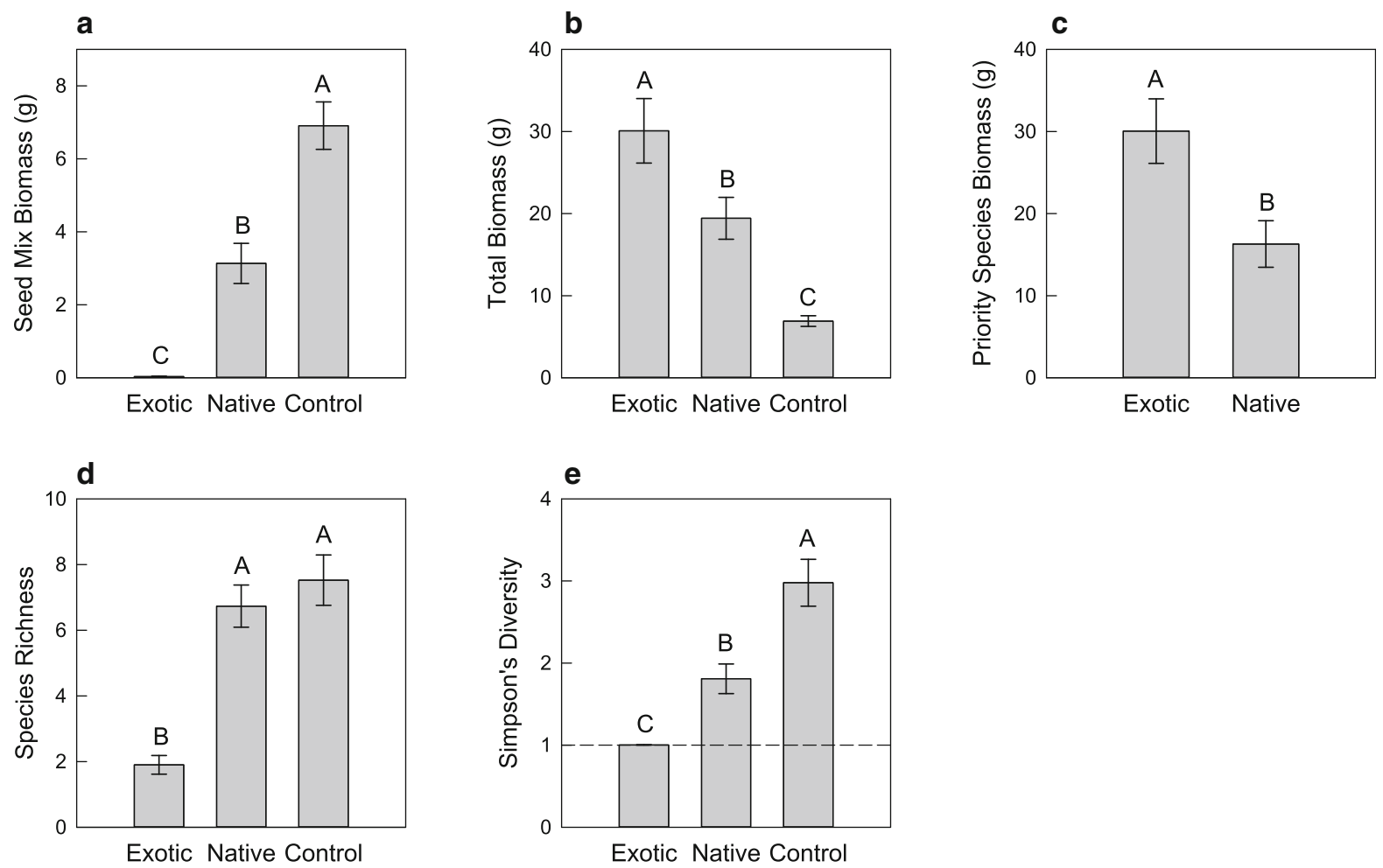

Fig. 1 Means \pm standard error across the species origin treatment (exotic, native, or control) on a seed mix biomass $(\mathrm{g})$, where seed mix biomass is the total biomass from a seed mix seeded 28 days after the priority species, b total biomass (g) where total biomass is the sum of seed mix biomass and priority species biomass, $\mathbf{c}$ priority species biomass (g) (controls

Total biomass

Total biomass (priority effect species + species from mix) was significantly different across priority species treatments (Fig. 1b), with no evidence for a difference due to water variability (Fig. 2b), nor an interaction between the two (Table 2). Exotic priority species treatments had significantly higher biomass than controls (Tukey's test, $p<0.001$ ) (Fig. 1b). Native priority species had intermediate total biomass to exotic priority species (Tukey's test, $p=0.048$ ) and control (Tukey's test, $p<0.001$ ) treatments.

\section{Priority species biomass}

Biomass of exotic priority species was significantly higher than native priority species across all water variability treatments $\left(F_{1,24}=10.96, p=0.003\right.$, Fig. 1c). Water variability treatments had no effect had no priority species and were not included), d species richness and e Simpson's diversity calculated as $\left(1 / \sum p_{i}^{2}\right.$ where $p_{\mathrm{i}}$ is relative abundance) with a dashed line indicating lower limit of 1. Letters denote significant differences based on Tukey's tests

on priority species biomass (Fig. 2c, Table 2). Biomass showed an insignificant interaction between water variability and priority species treatments $\left(F_{2,24}\right.$ $=3.28, p=0.055)$.

\section{Species diversity}

Priority species and water variability treatments caused significant differences in species diversity measures (Table 2). Species richness was significantly lower in exotics priority species treatments compared to control pots (Tukey's tests, $p<0.001$ ), and showed no difference between native priority species and control treatments (Fig. 1d). Simpson's diversity was also significantly lower in exotic priority species treatments compared to the control treatment (Tukey's test, $p<0.001$ ), and the native priority species treatments were intermediate to the control (Tukey's test, $p<0.001$ ) and exotic (Tukey's test, $p=0.016$ ) 

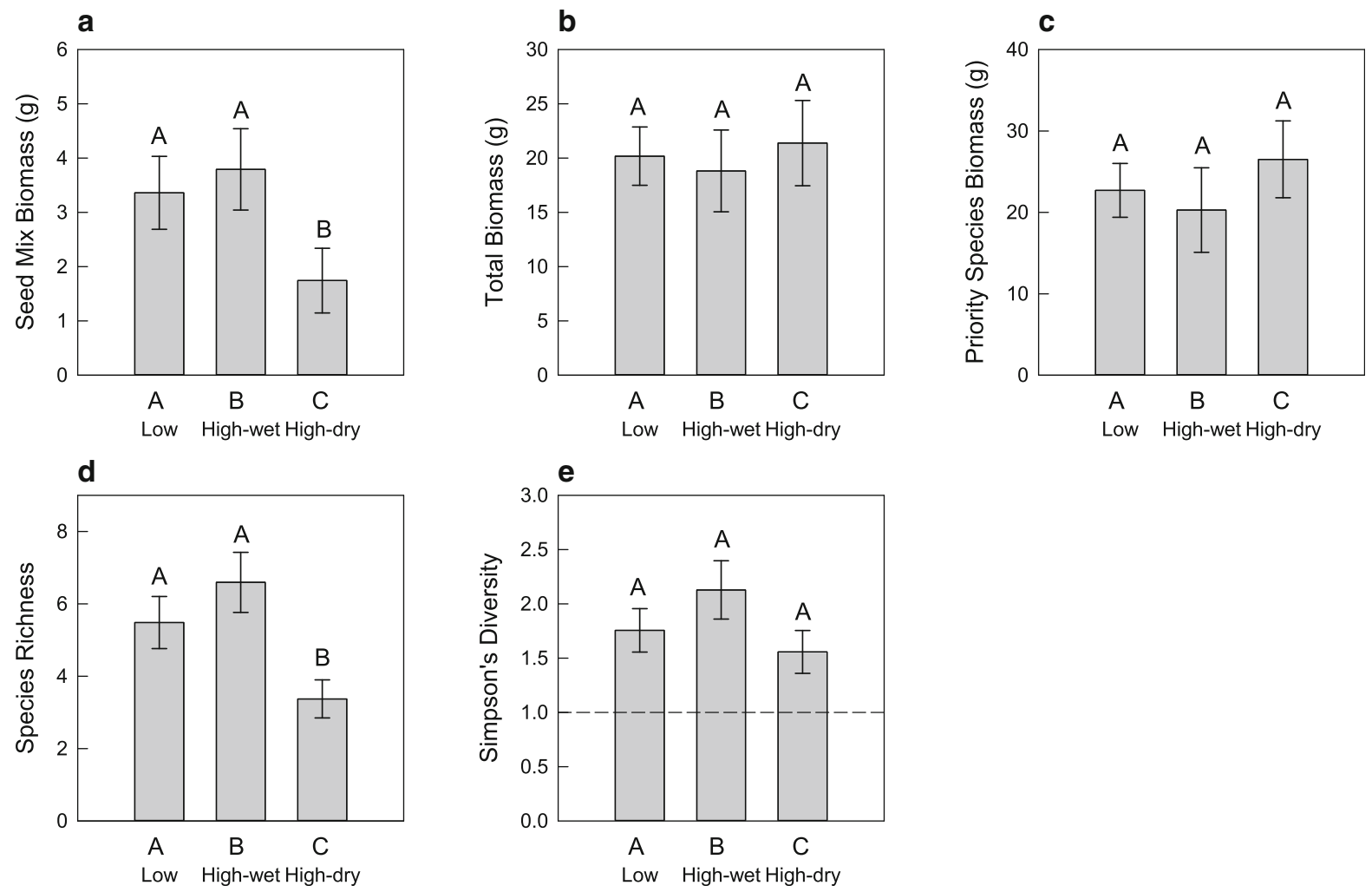

Fig. 2 Means \pm standard error across the water variability treatment $\left(\mathrm{A}_{\text {low }}, \mathrm{B}_{\text {High-wet }}\right.$, and $\left.\mathrm{C}_{\text {High-dry }}\right)$ on a seed mix biomass $(\mathrm{g})$ where seed mix biomass is the total biomass from the seed mix seeded 28 days following the priority species, b total biomass $(\mathrm{g}$ ) where total biomass is the sum of seed mix biomass and priority species biomass, $\mathbf{c}$ priority species biomass

treatments (Fig. 1e). Species richness was significantly different across water variability treatments $\left(F_{2,78}=10.25, p<0.001\right)$ where species richness was lowest in $\mathrm{C}_{\text {High-dry }}$ treatments (Fig. 2d). Water variability treatments had no effect on Simpson's diversity (Fig. 2e). Diversity measures showed no interactions between priority species and water variability (Table 2).

\section{Species composition}

Species composition of establishing species varied across priority species treatments. Priority species treatments had significantly different compositions ( $A=0.165, p<0.001$ ) (Online Resource 2). Water variability treatments showed no effect on species composition $(A=-0.004, p=0.572)$. Seed mix species present in exotic priority species treatment (g) (controls had no priority species and were not included), d species richness and e Simpson's diversity calculated as (1/ $\sum p_{i}^{2}$ where $p_{\mathrm{i}}$ is relative abundance) with a dashed line indicating lower limit of 1 . Letters denote significant differences based on Tukey's tests

communities were from multiple functional groups and were a subset of those in native and control treatments (Online Resource 1, Online Resource 2).

\section{Discussion}

Exotic grassland species had consistently larger priority effects than natives across all watering treatments. The exotic priority species maintained high biomass production regardless of water variability. The exotics ability to use increased resources early and maintain high levels of biomass regardless of the water treatment drove the priority effects in exotic dominated systems. Our results support the idea that exotics, and especially problematic invaders, have wide niche breadth (van Kleunen et al. 2015) which allows them to maintain dominance in a wide variety 
Table 3 Means and standard errors (untransformed) across priority species treatments (native, exotic, and control) and the water variability treatments $\left(\mathrm{A}_{\text {low }}, \mathrm{B}_{\text {High-wet }}\right.$, and $\left.\mathrm{C}_{\text {High-dry }}\right)$ for seed mix biomass (g), Species richness, Simpson's diversity, and total biomass (g) (priority species biomass + seed mix biomass), and priority species biomass (g). Seed mix biomass is the total biomass from a seed mix seeded 28 days after the priority species. Priority species biomass does not include controls. Both exotic and native priority species treatments had a sample size of 10 per water treatment, while the controls had a sample size of 7 per water treatment

\begin{tabular}{|c|c|c|c|c|c|c|c|c|c|c|c|}
\hline \multicolumn{2}{|l|}{ Treatment cross } & \multicolumn{2}{|c|}{$\begin{array}{l}\text { Seed mix } \\
\text { biomass }(g)\end{array}$} & \multicolumn{2}{|c|}{$\begin{array}{l}\text { Species } \\
\text { richness }\end{array}$} & \multicolumn{2}{|c|}{$\begin{array}{l}\text { Simpsons } \\
\text { diversity }\end{array}$} & \multicolumn{2}{|c|}{$\begin{array}{l}\text { Total biomass } \\
(\mathrm{g})\end{array}$} & \multicolumn{2}{|c|}{$\begin{array}{l}\text { Priority species } \\
\text { biomass }(\mathrm{g})\end{array}$} \\
\hline Priority species & Water variability & Mean & SE & Mean & SE & Mean & SE & Mean & SE & Mean & SE \\
\hline Exotic & $A_{\text {Low }}$ & 0.02 & 0.02 & 2.10 & 0.50 & 1.00 & 0.00 & 29.52 & 4.91 & 29.49 & 4.90 \\
\hline Exotic & $\mathrm{B}_{\text {High-wet }}$ & 0.07 & 0.03 & 2.40 & 0.65 & 1.01 & 0.00 & 34.07 & 8.15 & 34.00 & 8.15 \\
\hline Exotic & $\mathrm{C}_{\text {High-dry }}$ & 0.01 & 0.01 & 1.20 & 0.13 & 1.00 & 0.00 & 26.68 & 7.47 & 26.67 & 7.46 \\
\hline Native & $\mathrm{A}_{\text {Low }}$ & 3.74 & 0.81 & 7.90 & 1.07 & 1.96 & 0.38 & 19.67 & 3.14 & 15.93 & 3.47 \\
\hline Native & $\mathrm{B}_{\text {High-wet }}$ & 4.69 & 1.13 & 8.20 & 0.94 & 2.14 & 0.27 & 11.27 & 1.62 & 6.59 & 2.40 \\
\hline Native & $\mathrm{C}_{\text {High-dry }}$ & 0.99 & 0.41 & 4.10 & 0.90 & 1.33 & 0.25 & 27.36 & 6.01 & 26.37 & 6.18 \\
\hline Control & $A_{\text {Low }}$ & 7.59 & 0.71 & 6.86 & 1.12 & 2.54 & 0.34 & 7.59 & 0.71 & & \\
\hline Control & $\mathrm{B}_{\text {High-wet }}$ & 7.83 & 0.68 & 10.29 & 1.29 & 3.72 & 0.58 & 7.83 & 0.68 & & \\
\hline Control & $\mathrm{C}_{\text {High-dry }}$ & 5.31 & 1.61 & 5.43 & 0.95 & 2.67 & 0.48 & 5.31 & 1.61 & & \\
\hline
\end{tabular}

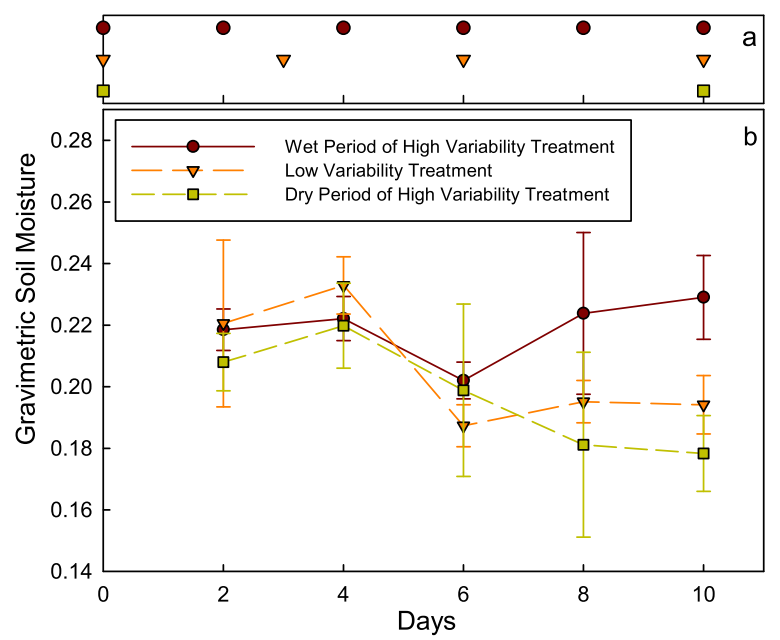

Fig. 3 Gravimetric soil moisture [(wet weight - dry weight)/ dry weight] across water frequency treatments. Panel a portrays the watering schedule, with dots representing when the pots were watered to field capacity. Wet periods of the high variability treatment pots were watered to field capacity every other day (samples were cored prior to watering) on days $0,2,4$,

of conditions. We also found support for the high productivity of exotics compared to native counterparts in grassland systems (Wilsey and Polley 2006), as exotic priority species showed much higher priority species biomass and total biomass than natives. The controls probably had lower total biomass as they were
6,8 , and 10 . Low variability treatments were watered to field capacity every 3 or 4 days on days $0,3,6$, and 10 . Dry periods of the high variability treatment were watered to field capacity once every 10 days on day 0 , and 10 . The 10 days represented are the last 10 days of the experiment, and were cored every other day for soil moisture

seeded 28 days later than priority species. Past research suggests that the consistently high priority effects across exotic species has been in part caused by human selection upon introduction, where humans preferentially introduced species with early emergence and establishment for grazing purposes (Mack 
and Lonsdale 2001; Wilkins and Humphreys 2003; van Kleunen et al. 2010). Wilsey et al. (2015) found exotic species had higher seedling emergence, earlier emergence, were taller and captured more light than native counterparts, which would give them a larger competitive advantage prior to seed mix additions. We suggest that in our system exotic species were able to maintain large priority effects due to both a larger head start in initial growth as well as the ability to resist unfavorable conditions throughout the growing season.

We hypothesized that increased water variability would lower priority effects and increase diversity. However, this was not consistent, as treatment $\mathrm{A}_{\text {low }}$ and $\mathrm{B}_{\text {High-wet }}$ showed no significant differences. Instead, we found evidence that timing was more important than variability, as the $\mathrm{C}_{\text {High-dry }}$ treatment resulted in significantly lower biomass from the seed mix and species richness. Soil moisture fell within the low end of the range for soil moisture during the growing season in our area, which produced some water stress in our pots (Martin and Wilsey 2006). Having a dry period early in the season could have created a strong abiotic filter on the ability of the seed mix to germinate and compete with the priority species. This, in turn, effectively increased the strength of priority effects for both native and exotic treatments. This is in line with Schantz et al. (2015) where lowered water stress was more beneficial for the annual competitors who arrived later than the early arriving perennials, diminishing priority effects despite less stressful conditions. If stress impacts later arrivers more than early arriving species, then priority effects will increase in strength.

Although we found no significant interactions between native and exotic priority species treatments and water variability treatments, results hint that natives may show larger responses to water variability than exotics. Increased sample sizes and power in future studies may reveal interactions between water variability timing and priority species origin. Trends show the greatest mean seed mix biomass for the native-species priority treatment in $\mathrm{B}_{\text {High-wet, }}$ while the seed mix biomass in the exotic species priority treatment was similarly low across water variability treatments $\left(F_{4,42}=2.33, p=0.071\right)$. In watering treatment $\mathrm{B}_{\text {High-wet }}$, later arriving species had higher resources (water) during germination and therefore competed more effectively with the early arrivers.
However, in conditions that were dry early (treatment $\mathrm{C}_{\text {High-dry }}$ ) late arrivers competed less effectively possibly due to less available resources on germination or waiting to germinate until later in the season. Additionally, mean priority species biomass was largest for the native priority species treatment in $\mathrm{C}_{\text {High-dry }}$ water variability and lowest in $\mathrm{B}_{\text {High-wet }}$, when exotic priority species had the highest mean biomass in the $\mathrm{B}_{\text {High-wet }}$ treatment $\left(F_{2,24}=3.28, p=\right.$ $0.055)$. Results hint that native priority species do not outcompete late arrivers as dominantly as exotic counterparts, and the seed mix was able to competitively impact native priority species in $\mathrm{B}_{\text {High-wet }}$ treatments when water was available early in the growing season. Changes in resources can alter competitive interactions when competitive differences between priority species and later arrivers are small. In a related study, Stuble and Souza (2016) found that the reduction in growth from arriving later was a result of both varied initial growth from priority species as well as the late arrivers' competitive ability. Similarly, Sarneel et al. (2016) recently found evidence in riparian systems for increased priority effect strength in dry or variable conditions compared to wet, possibly due to species specific responses as well as abiotic effects on both the early arriving species and later community. We encourage future studies to more closely examine interactions between priority effects, and abiotic variability and timing.

Our study does have some limitations that might limit the generality of our results. For better control, we used a greenhouse setting with grassland species over one growing season. Future research is needed in the field over multiple growing seasons. Priority effects were strong through one growing season, but how this translates to following year's growth is worth continued investigation, especially under varying water treatments. Although we focused on variability and all our pots received the same total amount of water, most field systems will vary in amount and timing simultaneously. It is also worth noting the differences in species composition across priority effect treatments are conservative, as monocultures were not included in the analysis, and would have very high dissimilarity with other communities.

In conclusion, we found that exotic perennial grassland species had consistently stronger priority effects than native perennial grassland species, regardless of water variability over the course of the growing 
season. Increasing water variability altered seed mix growth and species richness depending on the timing of water events rather than on the variability itself. Our results suggest that native community assembly may allow many different communities to form depending on which species arrives first and the timing of rainfall events over the growing season. This could lead to high beta diversity, which can be higher within nativedominated grassland fields than exotic dominated fields (Martin and Wilsey 2015). As weather patterns change, we may see many communities form based on weather events and resulting priority effect dynamics in native perennial grassland communities. However, our results suggest that exotic species may be having widespread priority effects in Central US grasslands regardless of changing precipitation patterns and timing.

Acknowledgements Funding support was provided by a Grant from the U.S. Department of Agriculture-National Institute of Food and Agriculture (2014-67003-22067). We would also like to thank two anonymous reviewers and Associate Editor Jesse Kalwij who made helpful comments on an earlier version of the manuscript.

Open Access This article is distributed under the terms of the Creative Commons Attribution 4.0 International License (http:// creativecommons.org/licenses/by/4.0/), which permits unrestricted use, distribution, and reproduction in any medium, provided you give appropriate credit to the original author(s) and the source, provide a link to the Creative Commons license, and indicate if changes were made.

\section{References}

Abraham JK, Corbin JD, D'Antonio CM (2009) California native and exotic perennial grasses differ in their response to soil nitrogen, exotic annual grass density, and order of emergence. Plant Ecol 201:445-456

Allan RP, Soden BJ (2008) Atmospheric warming and the amplification of precipitation extremes. Science 321:1481-1484

Berg P, Moseley C, Haeter JO (2013) Strong increase in convective precipitation in response to higher temperatures. Nat Geosci 6:181-185

Brandt AJ, Tanentzap AJ, Leopold DR, Heenan PB, Fukami T, Lee WG (2016) Precipitation alters the strength of evolutionary priority effects in forest community assembly of pteridophytes and angiosperms. J Ecol 104:1673-1681

Chase JM (2003) Community assembly: when should history matter? Oecologia 136:489-498

Collinge SK, Ray C (2009) Transient patterns in the assembly of vernal pool plant communities. Ecology 90:3313-3323
Dickson TL, Hopwood JL, Wilsey BJ (2012) Do priority effects benefit invasive plants more than native plants? An experiment with six grassland species. Biol Invasions 14:2617-2624

Fukami T (2015) Historical contingency in community assembly: integrating niches, species pools, and priority effects. Annu Rev Ecol Evol Syst 46:1-23

Grman E, Suding KN (2010) Within-year soil legacies contribute to strong priority effects of exotics on native California grassland communities. Restor Ecol 18:664-670

Harper JL (1961) Approaches to the study of plant competition. Mechanisms in biological competition. Academic Press Inc., New York

Houseman GR, Mittelbach GG, Reynolds HL, Gross KL (2008) Perturbations alter community convergence, divergence and formation of multiple community states. Ecology 89:2172-2180

Jarchow ME, Liebman M (2012) Nutrient enrichment reduces complementarity and increases priority effects in prairies managed for bioenergy. Biomass Bioenerg 36:381-389

Jones SK, Collins SL, Blair JM, Smith MD, Knapp AK (2016) Altered rainfall patterns increase forb abundance and richness in native tallgrass prairie. Sci Rep 6:20120

Kardol P, Souza L, Classen AT (2013) Resource availability mediates the importance of priority effects in plan community assembly and ecosystem function. Oikos 122:84-94

Kharin VV, Zwiers FW, Zhang X, Hegerl GC (2007) Changes in temperature and precipitation extremes in the IPCC ensemble of global coupled model simulations. J Clim 20:1419-1444

Knapp AK, Fay PA, Blair JM, Collins SL, Smith MD, Carlisle JD, Harper CW, Danner BT, Lett MS, McCarron JK (2002) Rainfall variability, carbon cycling, and plant species diversity in a mesic grassland. Science 298:2202-2205

Mack RN, Lonsdale WM (2001) Humans as global plant dispersers: getting more than we bargained for. Bioscience 51:95-102

Martin LM, Wilsey BJ (2006) Assessing grassland restoration success: relative roles of seed additions and native ungulate activities. J Appl Ecol 43:1098-1109

Martin LM, Wilsey BJ (2012) Assembly history alters alpha and beta diversity, exotic-native proportions, and functioning of restored prairie plant communities. J Appl Ecol 49:1436-1445

Martin LM, Wilsey BJ (2015) Novel, exotic-dominated grasslands exhibit altered patterns of beta diversity relative to native grasslands. Ecology 96:1042-1051

McCune B, Grace JB (2002) Analysis of ecological communities. MJM Software Design, Gleneden Beach

Morin PJ (1999) Community ecology. Blackwell Science, Oxford

Polley HW, Wilsey BJ, Derner JD, Johnson HB, Sanabria J (2006) Early-successional plants regulate grassland productivity and species composition: a removal experiment. Oikos 113:287-295

Sarneel JM, Kardol P, Nilsson C (2016) The importance of priority effects for riparian plant community dynamics. J Veg Sci 27:658-667 
Schantz MC, Sheley RL, James JJ (2015) Role of propagule pressure and priority effects on seedlings during invasion and restoration of shrub-steppe. Biol Invasions 17:73-85

Stuble KL, Souza L (2016) Priority effects: natives, but not exotics, pay to arrive late. J Ecol 104:987-993

Swearingen JM (2008) WeedUS: Database of plants invading natural areas in the United States. https://www.invasive. org/species/list.cfm?id=76. Accessed 3 Nov 2017

Topp GC (1993) Soil Water Content. In: Carter MR (ed) Soil Sampling and Methods of Analysis. Lewis Publishers, Boca Raton, pp 541-558

Tucker CM, Fukami T (2014) Environmental variability counteracts priority effects to facilitate species coexistence: evidence from nectar microbes. Proc $R$ Soc $B$ 281:20132637

Ulrich E, Perkins L (2014) Bromus inermis and Elymus canadensis but not Poa pratensis demonstrate strong competitive effects and all benefit from priority. Plant Ecol 215:1269-1275

van Kleunen M, Weber E, Fischer M (2010) A meta-analysis of trait differences between invasive and non-invasive plant species. Ecol Lett 13:235-245

van Kleunen M, Dawson W, Maurel N (2015) Characteristics of successful alien plants. Mol Ecol 24:1954-1968

Vaughn KJ, Young TP (2015) Short-term priority over exotic annuals increases the initial density and longer-term cover of native perennial grasses. Ecol Appl 25:791-799
Wainwright CE, Cleland EE (2013) Exotic species display greater germination plasticity and higher germination rates than native species across multiple cues. Biol Invasions 15:2253-2264

Wilkins PW, Humphreys MO (2003) Progress in breeding perennial forage grasses for temperate agriculture. J Agri Sci 140:129-150

Wilsey BJ, Polley HW (2006) Aboveground productivity and root-shoot allocation differ between native and introduced grass species. Oecologia 150:300-309

Wilsey BJ, Daneshgar PP, Polley HW (2011) Biodiversity, phenology and temporal niche differences between native and novel exotic - dominated grasslands. Perspect Plant Ecol Evol Syst 13:265-276. https://doi.org/10.1016/j. ppees.2011.07.002

Wilsey BJ, Barber K, Martin LM (2015) Exotic grassland species have stronger priority effects than natives regardless of whether they are cultivated or wild genotypes. New Phytol 205:928-937

Wolkovich EM, Cleland EE (2011) The phenology of plant invasions: a community ecology perspective. Front Ecol Environ 9:287-294

Young TP, Zefferman EP, Vaughn KJ, Fick S (2015) Initial success of native grasses is contingent on multiple interactions among exotic grass competition, temporal priority, rainfall and site effects. AoB PLANTS 7:plu081 